\title{
icH\&Hpsy 2018
}

$4^{\text {th }}$ International Conference on Health and Health

Psychology

\section{CONTRIBUTIONS TO UNDERSTANDING PORTUGUESE FACEBOOK CONSUMERS' BEHAVIOR: SOCIODEMOGRAPHICS, LIFESTYLE AND LIFE SATISFACTION}

\author{
Patrícia Araújo (a), Rosina Fernandes (b)*, Emília Martins (c), Francisco Mendes (d) \\ *Corresponding author \\ (a) IPAM/European University (Laureate International Universities), Porto, Portugal, pattaraujo@gmail.com \\ (b) Instituto Politécnico de Viseu e CI\&DETS, Viseu, Portugal, rosina@esev.ipv.pt \\ (c) Instituto Politécnico de Viseu e CI\&DETS, Viseu, Portugal, emiliamartins@esev.ipv.pt \\ (d) Instituto Politécnico de Viseu e CI\&DETS, Viseu, Portugal, fmendes@esev.ipv.ptt
}

\begin{abstract}
Facebook (FB), founded in 2004, is the most popular social networking site with more than 751 million users. Nevertheless, its relationship to lifestyle and satisfaction has only recently begun to be investigated. To analyze FB users' routines and understand its relationship with sociodemographic variables, such as lifestyle and satisfaction with life, a non-experimental study was undertaken. An online survey conducted between March and May 2016, integrated 23 questions about Facebook use. Detailed sociodemographic and lifestyle questions were also included as well as the Satisfaction with Life Scale. From the 136 individuals who participated, $82 \%$ were women, $64 \%$ were single, $76 \%$ were childless, $68 \%$ were employed and $40 \%$ had completed postgraduate studies. Descriptive and inferential analysis were performed using SPSS-24. Participants reported spending 1.79 hours/day on Facebook with unemployed participants spending more time than others. Single/divorced participants had more Facebook-friends and those who were childless accessed FB more times/day, in contrast to the older participants. FB use contributed to well-being more in men compared to women. Positive correlations were found between entries per day and perception that it causes work-related and social problems, in participants who showed higher motivation to close their FB account and less life satisfaction. Social media has become part of our lives in ways not yet well explored. Therefore, it is imperative to undertake research to uncover the positive and negative impacts of FB.
\end{abstract}

(C) 2018 Published by Future Academy www.FutureAcademy.org.UK

Keywords: Facebook, consumer behavior, sociodemographics, lifestyle, life satisfaction. 


\section{Introduction}

Consumer Psychology is a growing discipline within the field of applied psychology and emerged in the 60's with the birth of marketing. Consumer behaviour studies the processes which individuals and groups experience "when buying, using or disposing of services or ideas to satisfy their needs and wants" (Abreu \& Baptista, n.d., p. 3). Consumer decisions are influenced by personal factors such as age, occupation, economic status, personality, lifestyle and others (Teixeira, 2010).

In fact, lifestyle is crucial in determining consumer behavior. It refers to a pattern of consumption reflecting a person's choices of how he or she spends time and money, but in many cases it also refers to the attitudes and values attached to these behavioral patterns. Lifestyle "is more than the allocation of discretionary income ...it is a statement about who one is in society and who one is not" (Solomon, Bamossy, Askegaard, \& Hogg, 2006, p. 558). According to the authors, the lifestyle concept is one of the most widely used in modern marketing activities, as it provides a way to understand consumers' everyday needs and wants, and a mechanism to allow a product or service to be positioned in terms of how it will allow a person to pursue a desired lifestyle. A lifestyle marketing perspective "recognizes that people are increasingly conscious about the fact that we all sort ourselves and each other into groups on the basis of the things we/they like to do, how we/they like to spend our/their leisure time and how we/they choose to spend disposable income" (Solomon et al., 2006, p. 559-560). In the end, studying lifestyle is discovering how people spend their time, what they find interesting and important and how they view themselves and the world around them, as well as demographic information.

For this study, we chose to cross lifestyle information on FB consumers with the life satisfaction construct. Recent years have seen an increase in research on subjective well-being in general. Diener (2018) identifies three separable components of subjective well-being that have been identified as: positive affect, negative affect and life satisfaction. Whilst the first two components refer to the affective aspects of the construct, the latter refers to cognitive-judgmental aspects. According to this author, satisfaction with life can therefore be defined as a global assessment of a person's quality of life according to his/her chosen criteria. Judgments of satisfaction are dependent upon a comparison of one's circumstances with what is thought to be an appropriate standard. There are many factors influencing subjective well-being, including sociodemographic variables, such as, gender, age, marital status or household composition. Although in these studies, results are not always consistent, women tend to show higher levels of negative affectivity and subjective well-being is not necessarily lower in elderly (Thomsen, Mehlsen, Viidik, Sommerlund, \& Zachariae, 2005).

In order to understand the relationship between these constructs, namely consumer behaviour (in this case related to FB use), lifestyle and sociodemographic variables, we developed the study presented below.

Extensive literature shows that social relationships influence psychological well-being (Burke \& Kraut Robert, 2016) and specifically that face-to-face social interactions enhance well-being (Shakya \& Christakis, 2017). Online relationships and their effects, on the other hand, are still being explored. Although insufficiently studied, social networks have become increasingly popular and can be defined as networks of friends for social or professional interactions (Ho, 2014). Of all existing social networks, FB, 
founded in 2004 is the most popular, with more than 751 million active monthly users, making it the top social networking site, based on number of users and volume of access or use (Ho, 2014).

A study by Jha et al. (2016), with 452 students, concluded that the majority of the participants (84.1\%) accessed FB on a daily basis with $44.9 \%$ spending less than one hour daily on this social network. Most of the students $(76.8 \%)$ believed that FB had negatively affected their health and behaviour and two-third of the users admitted that it has had a negative impact on their studies. Burning eyes $(21 \%)$, disturbed sleep (19\%), and headache (16\%) were the most common adverse health effects reported by the FB users in this study.

Findings from Verduyn et al.'s (2015) experimental studies demonstrated that passive FB usage leads to decline in affective well-being. In one study, experimenters cued people in a laboratory to use FB passively (rather than actively) and concluded that this led to decline in affective well-being over time. A second replicant study demonstrated how this happens, using experience-sampling techniques by increasing feelings of envy.

In Vigil and Wu's (2015) study, the average respondent logged on 5-10 times per day, with sessions estimated to last between 5 and 10 minutes and they had 500+ Facebook friends. The authors were able to find many other correlations: (i) increased FB use was correlated to lower self-reported levels of happiness; (ii) respondents' interactions with photos and videos increased users' dissatisfaction. This phenomenon may be due to the impact photos have on the ways users engage in social comparisons with FB "friends" and the self-construals they create based on these comparisons; (iii) the more respondents reported using FB chat, the less satisfied they reported being with their lives; (iv) user interactions with photos was significantly correlated with adverse perceptions of life satisfaction; (v) time spent tagging photos and looking at others' photos/videos were significantly correlated with negative reports of life satisfaction; and (vi) there was a positive correlation between jealousy and the tendency to visit FB when feeling lonely. In this study, there was an overall negative relationship between time spent on FB and users' assessment with their lives. More time allocated toward actively engaging with photos tagging, uploading and looking at others' photos - was significantly negatively correlated with items such as "Life is generally fair," "My life is meaningful," "I have a good life," and "I am a happy person." However, uploading photos and tagging photos were positively correlated with respondents' professed happiness with their current life and life satisfaction was positively correlated with the number of all FB friends users have (Vigil \& Wu, 2015).

Shakya and Christakis (2017) conducted one of the largest studies in this field, searching for associations of both online and offline social networks with several subjective measures of well-being, using data of 5,208 people in a three wave $(2013,2014$, and 2015) study. Results showed that overall, the use of FB was negatively associated with well-being. For example, a 1-standard-deviation increase in "likes clicked" (clicking "like" on someone else's content), "links clicked" (clicking a link to another site or article), or "status updates" (updating one's own FB status) was associated with a decrease of $5 \%-8 \%$ of a standard deviation in self-reported mental health. On the other hand, nominating more real-world friends, feeling close to those friends, and interacting with them more frequently were associated with better mental health. Researchers found that using FB was associated with lower life satisfaction, whereas having real-life friends and interacting with them was associated with higher life satisfaction. Liking 
others' content and clicking links posted by friends were consistently related to compromised well-being, whereas the number of status updates was related to reports of diminished mental health. Authors included analyses on Body Mass Index (BMI) and found that FB use was associated with having a higher BMI. However, having a larger number of nominated friends, was associated with lower BMI (Shakya \& Christakis, 2017). In the study, although having a greater number of FB friends showed a positive correlation with well-being in the cross-sectional models, it did not retain significance in the longitudinal models.

A review article by Appel, Gerlach, and Crusius (2016) tried to establish a relationship between FB usage and depression, since the term 'Facebook Depression' has become increasingly used. But the available empirical evidence is equivocal, suggesting a positive, non-existent, or even a negative relationship between FB use and depression (Appel et al., 2016). Available evidence is largely consistent with the notion that Facebook use encourages unfavourable social comparisons and envy, which may in turn lead to depressed moods. However, although prospective and experience sampling studies as well as statistical modelling make this causal link plausible, these findings largely remain subject to the constraints of correlational data. Although data on FB depression is yet to be confirmed, Chow and Wan (2017), while exploring the moderating roles of neuroticism, envy and FB social comparison in the relationship between FB usage and depressive symptoms, in a sample of 282 participants, found a significant interactive effect between time spent on FB and neuroticism. The positive association between time spent on FB and depressive symptoms was only found among those high in neuroticism but not among those low in neuroticism (Chow \& Wan, 2017).

Although not FB specific, the study by Burke and Kraut (2016) suggests that people derive benefits from online communication, as long as it comes from people they care about and has been tailored for them. This study supports the idea that online interactions do influence well-being. Yet the effects depend on how people use the sites: simply reading about friends, receiving text communication from weak ties, and receiving one-click communication did not affect well-being, while receiving personalized, effortful communication from close friends was linked to improvements in well-being. This research proves a part of theory of belongingness in online relationships, that is that satisfaction will be greatest if the communication has strong ties (Burke \& Kraut Robert, 2016).

Taking into account these results, evidenced in the research on these themes, we present next the study that we developed in the Portuguese context in this scope.

\section{Problem Statement}

Although there is a growing field of research in social networking, there are still few scientific published papers analyzing FB habits and impacts on the general population, as well as its relationship with sociodemographic variables, lifestyle and, specifically, with life satisfaction. Furthermore, no study was found with a Portuguese population. In this sense, it is crucial to explore this consumer behaviour and its correlates in order to delineate intervention strategies in case there are less positive impacts of this behaviour. 


\section{Research Questions}

Given the problem statement presented before, the following research question was raised: what is the relationship between sociodemographic variables, lifestyle, satisfaction with life and FB use in Portuguese users? We also wanted to answer the following specific but secondary question: what are the characteristics of Portuguese FB users concerns with regard to their account use routines and perceptions about this social network, in terms of sociodemographic, lifestyle and subjective well-being dimensions? The answer to this secondary question will helps us to deepen our exploration of this theme.

\section{Purpose of the Study}

The purpose of this study was to analyse FB users' routines (time spent, number of friends, and others) and their perceptions (advantages/disadvantages of Facebook use and others) and the way this is related to their socio-demographic characteristics (gender, age, education level, occupation, marital status and others), lifestyle (eating habits, religion and others) and satisfaction with life.

\section{Research Methods}

An exploratory non-experimental study based on a quantitative methodology was developed.

\subsection{Participants}

Of the 136 individuals who participated, 82.4\% were women, aged between 18-58 (M=30.96, $\mathrm{SD}=10.07)$. Concerning family variables, $64 \%$ were without a spouse $(61 \%$ single and $3 \%$ divorced $)$, living in households between 1-6 family members and 75.7\% childless (number of children maximum = $3)$. In terms of occupational characteristics, 40 participants were unemployed and 83 employed (27 precarious workers, 21 with fixed term-contracts, 28 stable contracts, 6 entrepreneur/freelancer and 1 entrepreneur employing others); $30.1 \%$ considered themselves anemployed ${ }^{1}$. In terms of academic qualifications, 40.4\% reported postgraduate studies (26.47\% master and 13.97 doctoral degree), 29.41\% with a college degree and $28.68 \%$ had studied up to $12^{\text {th }}$ grade (only one participant had studied between $4^{\text {th }}$ and $6^{\text {th }}$ grade and another up to $9^{\text {th }}$ grade). We also explored religious choices and found that 52 were non-religious (49 atheists and 3 agnostics) and 84 with religion ( 81 Christians, 1 Buddhist and 2 espousing various other religions). Finally, four categories of dietary choices were reported by the participants: 104 omnivorous (I eat everything), 21 semi-omnivorous (I stopped eating some types of meat), 5 semi-vegetarian (I don't eat meat, only fish) and 6 ovo-lacto-vegetarian (I don't eat meat nor fish, but I still eat eggs, milk, etc.).

General sample characterization is presented in Table 01.

\footnotetext{
${ }^{1}$ Anemployment (in Portuguese, Inemprego) is a new concept in career research, described first by Araújo (2009, 2015, 2016 a, b, c, d) which is defined by the experience of work through precarious or atypical work relations alternating with periods of no-work (unemployment) throughout one's career.
} 
Table 01. Participant's characterization

\begin{tabular}{|c|c|c|c|c|c|}
\hline \multicolumn{2}{|r|}{ Variables } & Min. & Max. & M & SD \\
\hline \multicolumn{2}{|r|}{ Age } & 18 & 58 & 30.96 & 10.07 \\
\hline \multicolumn{2}{|c|}{ Household (number of family members) } & 1 & 6 & 2.87 & 1.24 \\
\hline & & \multicolumn{2}{|c|}{$\mathbf{n}$} & \multicolumn{2}{|c|}{$\%$} \\
\hline \multirow[t]{2}{*}{ Gender } & Male & \multicolumn{2}{|c|}{24} & \multicolumn{2}{|c|}{17.6} \\
\hline & Female & \multicolumn{2}{|c|}{112} & \multicolumn{2}{|c|}{82.4} \\
\hline \multirow{3}{*}{ Education } & Elementary to high school & \multicolumn{2}{|c|}{41} & \multicolumn{2}{|c|}{30.1} \\
\hline & Higher Education & \multicolumn{2}{|c|}{40} & \multicolumn{2}{|c|}{29.4} \\
\hline & Master and $\mathrm{PhD}$ & \multicolumn{2}{|c|}{55} & \multicolumn{2}{|c|}{40.4} \\
\hline \multirow{2}{*}{$\begin{array}{c}\text { Occupational } \\
\text { situation }\end{array}$} & Unemployed & \multicolumn{2}{|c|}{40} & \multicolumn{2}{|c|}{32.5} \\
\hline & Employed & \multicolumn{2}{|c|}{83} & \multicolumn{2}{|c|}{67.5} \\
\hline \multirow{2}{*}{ Marital Status } & With spouse & \multicolumn{2}{|c|}{49} & \multicolumn{2}{|c|}{64} \\
\hline & Without spouse & \multicolumn{2}{|c|}{87} & \multicolumn{2}{|c|}{36} \\
\hline \multirow{2}{*}{ Children } & Yes & \multicolumn{2}{|c|}{33} & \multicolumn{2}{|c|}{24.3} \\
\hline & No & \multicolumn{2}{|c|}{103} & \multicolumn{2}{|c|}{75.7} \\
\hline \multirow{2}{*}{ Religion } & Yes & \multicolumn{2}{|c|}{84} & \multicolumn{2}{|c|}{61.8} \\
\hline & No & \multicolumn{2}{|c|}{52} & \multicolumn{2}{|c|}{38.2} \\
\hline & Omnivore & & & & \\
\hline Dietary choices & Other & & & & \\
\hline
\end{tabular}

\subsection{Materials}

Using Google forms data was collected using a structured self-administered online questionnaire specially developed for the research. The methodological choice of using electronic data collection has been proved to be scientifically valid, since no significant differences have been found between electronic and paper collection of data (Fernandes, 2013). Furthermore, since the only criteria to participate was to have a FB account, an online questionnaire seemed ideal to reach more participants.

The questionnaire aimed to collect several socio-demographic (age, gender, number of children, house holding, academic level and employment status -6 items) and lifestyle data (e.g. dietary and religious choices -2 items), as well as the consumer's experience with FB and related habits (23 items).

The Portuguese version (Simões, 1992) of Diener, Emmons, Larsen and Griffin (1985) Satisfaction with Life scale (SWLS) was also used. SWLS includes five items answered in a five-point Likert scale ( 1 - strongly disagree to 5 - strongly agree), where participants with higher scores point to better results in the cognitive dimension of well-being (satisfaction with life). The instrument presents good psychometric qualities with a Cronbach's alpha coefficient of .77 , as well as convergent and predictive validity (Gomes, 2015).

\subsection{Procedures}

The questionnaire was made available to participants from 23rd of March to 10th of May 2016. Participants were informed of the objectives of the study, the voluntary nature of participation and anonymity. Google Forms tool allows direct share of the link on FB but researchers also used the directed link tool to divulge it through other networks. 
Descriptive and inferential data analysis were performed in Statistical Package for Social Sciences (IBM 24) with a confidence level of 95\%. Non-parametric tests were used due to the characteristics of the sample (non-compliance of normality and/or homoscedasticity) and of the variables explored (Pestana \& Gageiro, 2008).

\section{Findings}

The results are presented starting from the secondary question defined for this study (Facebook Portuguese users profile), that will enable the subsequent understanding of the inferential results, presented next, related to the main question of study (relationship between FB consumer behaviour and socio-demographics, lifestyle and life satisfaction).

\subsection{Descriptive results}

Of the 136 Portuguese FB users in our sample, 96.3\% had internet connection at home.

Regarding Facebook access, 61.8\% consulted their account everywhere, on average of 6.93 times $( \pm 8.67)$ per day and generally for more than one and a half hours per day $(\mathrm{M}=107.41, \mathrm{SD}=120.77$; in minutes), with a great dispersion of results in this scope of the number and time of access to FB. In the self-evaluation about their degree of participation on FB, in a scale from 1 (not participative at all) to 5 (very participative), Portuguese users presented a mean value of $2.55( \pm .78)$, considering themselves as 'more or less participative'. The average values presented for FB and real-life friends were substantially different (about 10 times more in the virtual world), respectively: $\mathrm{M}=592.43, \mathrm{SD}=456.57$ vs. $\mathrm{M}=$ $56.95, \mathrm{DP}=202.42$

When asked if FB contributes to their good humour during the day, if helps to cope with stress and specially with work related stress, in a scale from 1 (not at all) to 5 (a lot), mean values were $2.02( \pm .84)$, $1.94( \pm .85)$ and $2.11( \pm .93)$, respectively. In this sense, the participants do not seem to identify these aspects as benefits inherent to the use of this social network. Regarding perception of problems caused by Facebook, the sample feel that FB, also in the same scale from 1 to 5, does not cause work related $(\mathrm{M}=1.30, \mathrm{DP}=.61)$ or social and personal problems $(\mathrm{M}=1.74, \mathrm{DP}=.88)$, or stress $(\mathrm{M}=1.82, \mathrm{DP}=.87)$. Concerning the balance between advantages and disadvantages, $60.3 \%$ of Portuguese users feel that FB has brought as much advantages as disadvantages to people's lives.

To complement this FB's use/perceptions descriptive analysis, we also wanted to know how many participants considered closing their account: 39.7\% never considered it, $32.4 \%$ considered it occasionally, $19.1 \%$ sometimes considered it and only $8.8 \%$ frequently considered closing their Facebook account. In sum, $60.3 \%$ have considered closing their account.

These descriptive analyses are presented in Table 02 .

Table 02. Descriptive analysis on Facebook use routines and perceptions

\begin{tabular}{|ccccc|}
\hline Variables & Min. & Max. & M & SD \\
\hline Number of accesses per day & 0 & 50 & 6.93 & 8.675 \\
\hline Time spent per day (minutes) & 0 & 750 & 107.41 & 120.77 \\
\hline
\end{tabular}




\begin{tabular}{|c|c|c|c|c|c|c|}
\hline \multicolumn{3}{|c|}{ Participation level } & 1 & 4 & 2.55 & .78 \\
\hline \multicolumn{3}{|c|}{ Number of virtual friends } & 40 & 3000 & 592.43 & 456.57 \\
\hline \multicolumn{3}{|c|}{ Number of real life friends } & 0 & 2000 & 56.95 & 202.42 \\
\hline \multirow{3}{*}{\multicolumn{2}{|c|}{ Facebook Advantages }} & good humour & 1 & 4 & 2.02 & .84 \\
\hline & & cope with stress & 1 & 4 & 1.94 & .85 \\
\hline & & $\begin{array}{c}\text { cope with work related } \\
\text { stress }\end{array}$ & 1 & 4 & 2.11 & .93 \\
\hline \multirow{4}{*}{\multicolumn{2}{|c|}{ Facebook Disadvantages }} & causes stress & 1 & 4 & 1.82 & .87 \\
\hline & & $\begin{array}{l}\text { causes social and } \\
\text { personal problems }\end{array}$ & 1 & 4 & 1.74 & .88 \\
\hline & & $\begin{array}{c}\text { causes work related } \\
\text { problems }\end{array}$ & 1 & 4 & 1.30 & .61 \\
\hline & & & \multicolumn{2}{|c|}{$\mathbf{n}$} & \multicolumn{2}{|c|}{$\%$} \\
\hline \multirow{5}{*}{ Facebook access } & & every places & \multicolumn{2}{|c|}{84} & \multicolumn{2}{|c|}{61.8} \\
\hline & & work & \multicolumn{2}{|c|}{2} & \multicolumn{2}{|c|}{1.5} \\
\hline & & home & \multicolumn{2}{|c|}{25} & \multicolumn{2}{|c|}{18.4} \\
\hline & & home and work & \multicolumn{2}{|c|}{22} & \multicolumn{2}{|c|}{16.2} \\
\hline & & ic places with internet & \multicolumn{2}{|c|}{3} & \multicolumn{2}{|c|}{2.2} \\
\hline \multirow{3}{*}{$\begin{array}{c}\text { Facebook } \\
\text { advantages and } \\
\text { disadvantages } \\
\text { balance }\end{array}$} & & $\begin{array}{l}\text { much advantages as } \\
\text { disadvantages }\end{array}$ & \multicolumn{2}{|c|}{82} & \multicolumn{2}{|c|}{60.3} \\
\hline & mor & $\begin{array}{l}\text { DISAVANTAGES than } \\
\text { advantages }\end{array}$ & \multicolumn{2}{|c|}{13} & \multicolumn{2}{|c|}{9.6} \\
\hline & mo & $\begin{array}{l}\text { ADVANTAGES than } \\
\text { disadvantages }\end{array}$ & \multicolumn{2}{|c|}{41} & \multicolumn{2}{|c|}{30.1} \\
\hline \multirow{4}{*}{$\begin{array}{c}\text { Close Facebook } \\
\text { account }\end{array}$} & & never thought & \multicolumn{2}{|c|}{54} & \multicolumn{2}{|c|}{39.7} \\
\hline & & think occasionally & \multicolumn{2}{|c|}{44} & \multicolumn{2}{|c|}{32.4} \\
\hline & & sometimes think & \multicolumn{2}{|c|}{26} & \multicolumn{2}{|c|}{19.1} \\
\hline & & think frequently & \multicolumn{2}{|c|}{12} & \multicolumn{2}{|c|}{8.8} \\
\hline
\end{tabular}

Within the scope of the description of the Portuguese Facebook users profile (secondary specific question defined in this study), besides the routines and perceptions about this social network (presented above), a set of sociodemographic and lifestyle characteristics (more specifically, dietary and religious options) was presented in participants' characterization, and it remains only to present the results related to the cognitive dimension of subjective well-being, namely satisfaction with life. In this sense, the mean value found in this sample was adequate $(\mathrm{M}=17.07, \mathrm{SD}=3.82)$.

\subsection{Inferential results}

The inferential results are presented in a tripartite manner, considering the dimensions under analysis in the participants' relationship with the use of FB: sociodemographic variables, lifestyle and life satisfaction, but first, an exploratory analysis was conducted concerning FB user's routines and perceptions

The highest participatory users said that FB contributes to making them feel well-disposed during the day $(r S=.384, p=.000)$, helping to cope with life $(r S=.300, p=.000)$ and work $(r S=.209, p=.029)$ stress, pointing out, however, that despite these advantages, FB also brings more personal and social problems $(r S=.180, p=.036)$. There was a statistically significant and positive correlation, although 
weak, between the number of friends on FB compared to those in real life $(r S=.181, p=.038)$, and the more friends on FB, the more times per day the participants accessed FB $(r S=.270, p=.002)$, the more they considered themselves to be more participatory users $(r S=.270, p=.002)$. In general, the more accesses per day, the longer they claim to spend on Facebook $(r S=.478, p=.000)$.

\subsubsection{Facebook consumer's behaviour and sociodemographic variables}

Unemployed participants spent more time (in minutes) per day (127.7 \pm 126.1 vs. 96.6 \pm 123.5$)$ on FB than those who were working $(U=1256.5, p=.028)$. In turn, the single and divorced users claimed to have more friends on FB $(635.6 \pm 448.6$ vs. $515.6 \pm 465.0)$ than married ones $(U=1544.0, p=.008)$. The existence of children was significant in the number of FB interactions per day $(U=1019.5, p=.013)$; it

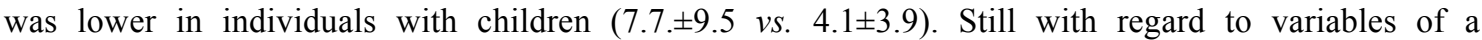
sociodemographic nature, a statistically significant and negative correlation was found to be weak, according to the Marôco classification (2014), between age and number of accesses per day to FB ( $r S=$ $.243, p=.006)$, the oldest assuming themselves to be less participatory $(r S=-.185, p=.031)$. Finally, with regard to the gender, this variable proved to be significant only in the importance of FB for the good humour $(U=1009.5, p=.043)$ that was superior in males $(1.9 \pm .84$ vs. $2.3 \pm .81)$.

\subsubsection{Facebook consumer's behaviour and lifestyle}

Omnivores spent more time per day $(114.5 \pm 123.2$ vs. 84.0 \pm 110.8 , in minutes $)$ on $\mathrm{FB}(U=1239.5$, $p=.028)$ and declared themselves more participatory users $(U=1078.0, p=.001)$ than participants with

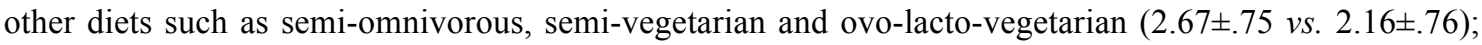
the latter perceived $(2.13 \pm .97 v s .1 .72 \pm .81)$ that FB causes them additional stress $(U=1276.5, p=.033)$,

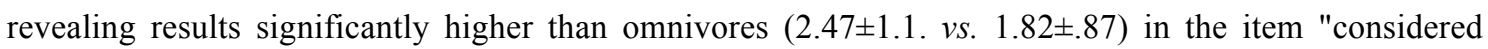
closing their Facebook account" ( $U=1107.0, p=.003)$. Contrary to the diet options, religion did not prove to be statistically related to the use of FB.

\subsubsection{Facebook consumer's behaviour and satisfaction with life}

Participants who spent more time per day on FB presented higher values in "contributes to making me feel better during the day" ( $r S=.172, p=.046)$, but also in "brings personal and social problems" ( $r S$ $=.249, p=.003)$, revealing less satisfaction with life $(r S=-278, p=.001)$. Moreover, those who reported more personal and social problems, also reported higher work-related problems $(r S=.390, p=.000)$. These subjects who reported more work-related problems associated with FB use demonstrated a higher tendency to close the account $(r S=.344, p=.000)$ and less satisfaction with life $(r S=-.204, p=.017)$.

\section{Conclusion}

In sum, in this exploratory study, participants reported being on FB almost two hours/day, with the unemployed spending more time on FB, a higher access rate among the childless and younger and single/divorced participants having more Facebook-friends. In this sense, the results reveal that the 
younger generation and people with a smaller social support network, both in family and work life, seem to present a higher FB consumption behavior. We believe that it is understandable that people without professional occupation end up occupying their free time also in social networks. The same justification can be applied to the participants without children and with more available time to spend on this activity. Concerning higher access rate among young people, given that they have grown up in an era in which social networks are part of everyday life, their greatest interest will be natural when compared to other generations.

Although users highlighted benefits inherent to this social network, they also identified problems both personal and work-related. It can be concluded that a judicious use of FB with balance, common sense and in a controlled way day to day, can work as a positive distraction promoting well-being, especially in men. Diet choices revealed some impact in this behavior with omnivores being more participative. We know that food choices focused on Eastern philosophies, such as vegetarianism/veganism, for example, go beyond mere food selection and broaden the lifestyle of communion with nature, which is naturally away from technological world, but we think it's crucial to deepen this question.

This study, besides allowing to characterize Portuguese FB users' routines, did highlight a strong relationship with socio-demographic characteristics, lifestyle and satisfaction with life. Hence, it is fundamental to proceed with more research in this area to deepen understanding on the positive and negative impact of FB on life, because social media has become part of our lives, impacting personal and work dimensions in ways not yet explored. Future studies should include participants that do not use social network, consumers of other social network sites and comparisons between countries.

\section{Acknowledgments}

We are grateful to the Centre for Studies in Education, Technologies and Health (CI\&DETS) at the Polytechnic Institute of Viseu, Portugal for its assistance in conducting this study.

\section{References}

Abreu, K., \& Baptista, P. (n.d.). Publicidade e Comportamento do Consumidor: alguns apontamentos. Retrieved from www.bocc.ubi.pt

Appel, H., Gerlach, A., \& Crusius, J. (2016). The interplay between Facebook use, social comparison, envy, and depression (Vol. 9).

Araújo, P. (2009). Os inempregáveis: Estudos de caso sobre os impactos psicossociais do nao-emprego em licenciados portugueses. [Dissertação de Mestrado]. Porto: Faculdade de Psicologia e de Ciências da Educação da Universidade do Porto.

Araújo, P. (2015). Multiplasticity: A Grounded Theory on the Adaptation to Anemployment. (Doctoral Thesis), Faculdade de Psicologia e de Ciências da Educação da Universidade do Porto, Porto.

Araújo, P., Jordão, F., \& Castro, J. (2016a). The Anemployment Profiles in Portugal. In A. R. Sánchez, M. V. Fernández, \& L. R. Agraso (Eds.), A formación, a orientación e o emprego no recoñecemento, avaliación e certificación das competencias profesionais adquiridas en contextos formais, non formais e informais. Santiago de Compostela: Universidad de Santiago de Compostela. 
Araújo, P., Jordão, F., \& Castro, J. (2016b). Multiplasticity: A Grounded Theory on the Adaptation to Anemployment [Multiplasticity: A grounded theory on graduate's adaptation to anemployment]. Labour Sciences Journal [Revista Ciências do Trabalho](6), 37-62.

Araújo, P., Jordão, J., \& Castro, J. (September, 2016). Careers in the Health Sector: Anemployment Effects In Health Professionals. Paper presented at the 3rd World Congress of Health Research, Escola Superior de Saúde, Viseu, Portugal.

Araújo, P., Jordão, J., \& Castro, J. (2016d). Quality Of Life in Higher Education Graduates: The Effects of Anemployment. Paper presented at the 3rd World Congress of Health Research, Viseu, Portugal.

Burke, M., \& Kraut R, E. (2016). The Relationship Between Facebook Use and Well Being Depends on Communication Type and Tie Strength. Journal of Computer-Mediated Communication, 21(4), 265-281. doi:10.1111/jcc4.12162

Chow, T., \& Wan, H. (2017). Is there any 'Facebook Depression'? Exploring the moderating roles of neuroticism, Facebook social comparison and envy. Personality and Individual Differences, 119, 277-282. doi:DOI10.1016/j.paid.2017.07.032

Diener, E. (2018). Happiness: the science of subjective well-being. In R. Biswas-Diener \& E. Diener (Eds), Noba textbook series: Psychology. Champaign, IL: DEF publishers.

Diener, E., Emmons, R., Larsen, R., \& Griffin, S. (1985). The Satisfaction with life Scale. Journal Personality Assessement, 49(1), 71-75.

Fernandes, R. (2013). Bem-estar subjetivo no (des)emprego: um estudo sobre o ajustamento pessoaambiente profissional (Tese de Doutoramento). Coimbra: Faculdade de Psicologia e de Ciências da Educação da Universidade de Coimbra.

Gomes, C. (2015). A Influência do Meio Ecológico na Experiência da Solidão E No Bem-Estar Subjetivo, Numa Amostra de Adultos Mais Velhos. (Mestrado Integrado em Psicologia), Universidade de Lisboa, Lisboa.

Ho, C. (2014). Consumer behavior on Facebook: Does consumer participation bring positive consumer evaluation of the brand? EuroMed Journal of Business, 9(3), 252-267. doi:10.1108/EMJB-122013-0057

Jha, R. K., Shah, D. K., Basnet, S., Paudel, K. R., Sah, P., Sah, A. K., \& Adhikari, K. (2016). Facebook use and its effects on the life of health science students in a private medical college of Nepal. BMC Research Notes, 9, 378. doi:10.1186/s13104-016-2186-0

Marôco, J. (2014). Análise estatística: com a utilização do SPSS. Lisboa: Sílabo.

Pestana, M., \& Gageiro, J. (2008). Análise de dados para ciências sociais: a complementaridade do SPSS (5. ${ }^{a}$ ed.). Lisboa: Europress.

Shakya, H. B., \& Christakis, N. A. (2017). Association of Facebook Use with Compromised Well-Being: A Longitudinal Study. American Journal of Epidemiology, 185(3), 203-211. doi:10.1093/aje/kww189

Simões, A. (1992). Ulterior validação de uma escala de satisfação com a vida (SWLS). Revista Portuguesa de Pedagogia, 26(3), 503-515.

Solomon, M., Bamossy, G., Askegaard, S., \& Hogg, K. (2006). Consumer Behaviour: A European Perspective (3rd ed.): Pearson Education/Prentice Hall/Financial Times.

Teixeira, J. (2010). Fatores que influenciam o comportamento do consumidor (Monografia de PósGraduação). Instituto A Vez do Mestre da Universidade Cândido Mendes, Brasil.

Thomsen, D., Mehlsen, M., Viidik, A., Sommerlund, B., \& Zachariae, R. (2005). Age and gender differences in negative affect - Is there a role for emotion regulation? Personality and Individual Differences, 38(8), 1935-1946.

Verduyn, P., Lee, D., Park, J., Shablack, H., Orvell, A., Bayer, J., . . Kross, E. (2015). Passive Facebook usage undermines affective well-being: Experimental and longitudinal evidence. Journal of Experimental Psychology: General, 144(2), 480-488. doi:http://dx.doi.org/10.1037/xge0000057

Vigil, T., \& Wu, H. (2015). Facebook Users' Engagement and Perceived Life Satisfaction. Media and Communication, 3(1), 5-16. doi:10.17645/mac.v3i1.199 